\title{
Insect Biodiversity as an Asset Rather than a Burden
}

\section{Abaker M Malik*}

Pest Management Specialist, Plant Protection Directorate, Sudan

*Corresponding Author: Abaker M Malik, Pest Management Specialist, Plant Protection Directorate, Sudan.
Received: May 26, 2021

Published: June 30, 2021

(C) All rights are reserved by Abaker M Malik.
Most diverse on group on earth are insects not only but they also play several significant roles in environmental system post and the universal economy. Thus, insect diversity is a key topic worldwide. Insects pollinate blossoms, some of them have great value as ecotourism venture, because of their articulateness and susceptibility to environmental factors many insects can be used as bio-indicators, for example, butterflies have been suggested as indicators [1]. An important component of the human diet, many insect species have been identified as food and feed [2]. Insects can play role as recyclers of biowastes [3]. One of the most consequential application of insects is biological pest management agents; insect predators are known to be more potent than many chemicals in controlling economically damaging insects [1]. Many people are oblivious to the indispensable roles played by insects in our lives.

\section{Pollination}

Pollination is a vital ecological service that contribute to the yields worldwide. Thus, bees, wasps, flies, beetles, butterflies and moths make important contributions to agriculture. Worldwide $35(\%)$ of Agriculture depend on them and 87 (\%) which are five times more valuable than those that do not need pollination and supporting $87(\%)$ of leading food crops [4].

\section{Ecotourism}

Insects are not typically thought of as an emerging market in the ecotourism world, but with some investigation, it appears that insects could surface as a key attraction in many nature-based tourism enterprises i.e., an increasingly common trend is for adult butterflies to be released at events such as weddings, funerals, birthdays, and even grand openings of stores [5].

\section{Bioindicators}

Class Insecta has many appropriate species which can be used as a indicator and guideline about levels of variation in the environmental services viz., Odonata (dragonflies), Beetles from Order Coleoptera, moths and butterflies (Lepidoptera), Ants, etc, that because of conspicuousness responses to the disturbances. Pollina- tors, particularly bees i.e., Apis mellifera, are providing credible biological analysis because of their vulnerability to the environment conditions with high mortality rate [6].

\section{Food and feed}

Unlike other sources of protein, eatable insects can assort the diets, enhance livelihoods and contribute to food security with lower ecological footprint. Insect's farming is motivated by the rising interest in exploring alternative sources of food that are both nutritious and environmentally sustainable and combined with these potential benefits of edible insects [7]. Abundant insects have demonstrated possibility for exploitation as a nutrient source and deserving further extensive investigation viz., Termites, Locusts [2], White grubs [8], silkworms [9], etc. Super worm Zophobas morio (Coleoptera: Tenebrionidae) which has been overlooked by researchers recently recognized as potential food and feed [10].

\section{Waste management}

One of the best examples of the waste decomposers is the larval stage of Black soldier fly (BSF) which is capable of bioconversion of organic wastes in a short time. Can reduce the organic waste biomass to tune of $50-95 \%$. BSF is neither a pest nor a vector (detritivorous) and does not cause any harm [3].

\section{Pest management}

The natural enemy presumption expected that in polycultures the abundance and diversity of natural enemies of pest insects will be a bigger than in monocultures [11]. Heterogeneous environment (polyculture) expected to encounter a greater matrix of alternative prey and microhabitats which match with the polyphagous insects needs like predators.

Annual crop monocultures do not provide enough alternative sources of food (pollen, nectar, prey), shelter, breeding and nesting sites for the effective performance of natural enemies [12] 
The invisibleness of insects would mean the loss of a vital food source without which most mammals, reptiles and amphibians would die. Blossoming plants which bestrewed most of the earth surface would be incapable to stet without insects facilitating their upper and below soil conditions. The earth crust would be bestrewed with dead plants and animals, and only wild pollinated plants and very little animal life would sustain. Mankind would not last more than few months. The dramatic change in the industry, the rapid population growth and its serious economic consequences have caused a sensational loss in universal biodiversity, resulting in large unrest to environmental systems and our standard of comfort. Correspondingly, most important challenge on our planet is the conservation of biodiversity. There is a need of rethought of current agricultural practices, especially a serious retrenching in pesticide usage and its replacement with more sustainable, ecologically friendly based practices, to slow or invert current trends, allow the uptrend of declining insect populations and safeguard the vital ecosystem services they furnish.

\section{Bibliography}

1. Abaker M M and Vijaya. "Insect Biodiversity as an Asset Rather Than A Burden". CCSHAU, HISAR, INDIA. BES 114: National Seminar on "Biodiversity: Issues, Challenges and Opportunities" (2019).

2. Abaker M M., et al. "Utilization of desert locust as food in Sudan. National Symposium on Recent Advances in Beneficial Insects". Natural Resins and Gums, February (2021): 116.

3. Yandigeri M., et al. "Black soldier fly - a detritivorous insect for solid waste management" (2019).

4. FAO. The importance of bees and other pollinators for food and agriculture. FAO's work on pollinators (2018).

5. Whelan J C. "Experiments with Entomological Ecotourism Models and The Effects of Ecotourism on The Overwintering Monarch Butterfly (Danaus Plexippus)". PhD Thesis submitted to the University of Florida (2012).

6. Rocha jR., et al. "Insects as Indicators of Environmental Changing and Pollution: A Review of Appropriate Species and Their Monitoring". HOLOS Environment 10.2 (2010): 250.

7. FAO. "Looking at edible insects from a food safety perspective". Challenges and opportunities for the sector. Rome (2021).

8. Pilania S., et al. "Anthropoentomophagy: White grub-A promising edible insect". National Symposium on Recent Advances in Beneficial Insects, Natural Resins and Gums, February (2021): 117-118.
9. Yadav S., et al. "Silkworm pupae meal as a good source of protein in fish feed". National Symposium on Recent Advances in Beneficial Insects, Natural Resins and Gums, February (2021): 116.

10. Rumbos CI and Athanassiou CG. "The Superworm, Zophobas morio (Coleoptera:Tenebrionidae): A 'Sleeping Giant' in Nutrient Sources". Journal of Insect Science 21.2 (2021): 1-11.

11. Root R B. "Organization of a plant-arthropod association in simple and diverse habitats: the fauna of collards (Brassica oleracea)". Ecological Monographs 43 (1973): 95-124.

12. Rabb R L., et al. "Conservation and augmentation of natural enemies". In 'Theory and Practice of Biological Control' (C. B. Huffaker and P. Messenger, eds). Academic Press, New York (1976): 233-254.

\section{Volume 5 Issue 7 July 2021}

(C) All rights are reserved by Abaker M Malik. 